\title{
Socioeconomic inequality and child maltreatment in Iranian schoolchildren
}

\author{
Z. Hosseinkhani, ${ }^{1,2}$ S. Nedjat, ${ }^{2}$ A. Aflatouni, ${ }^{3}$ M. Mahram ${ }^{7}$ and R. Majdzadeh ${ }^{2}$
}

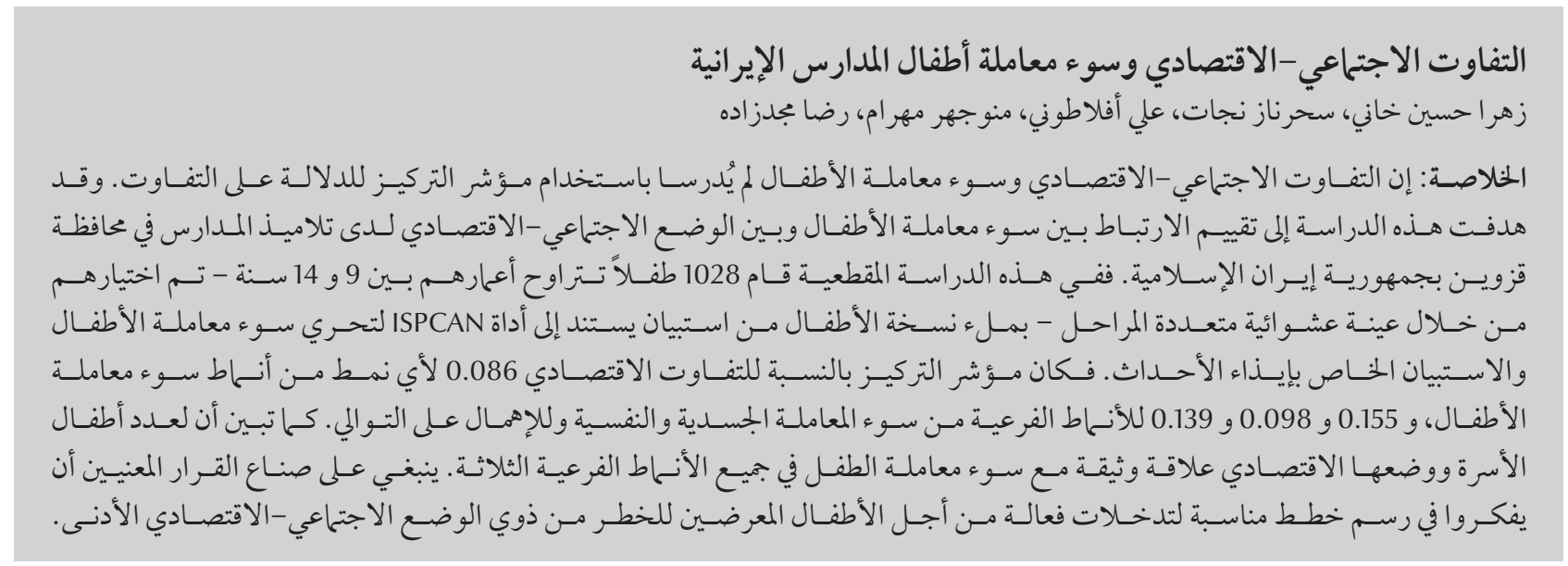

ABSTRACT Socioeconomic inequality and child maltreatment have not been studied using the concentration index as an indicator of inequality. The study aimed to assess the association of child maltreatment with socioeconomic status among schoolchildren in Qazvin province, Islamic Republic of Iran. In this cross-sectional study a questionnaire based on the ISPCAN Child Maltreatment Screening Tool-Children's Version and the Juvenile Victimization Questionnaire was filled by 1028 children aged 9-14 years, selected through multistage stratified random sampling. The concentration indices for economic inequality were -0.086 for any type of child maltreatment and $-0.155,-0.098$ and -0.139 for the physical, psychological and neglect subtypes of maltreatment respectively. The number of children and the economic status of the family also showed a significant association with child maltreatment in all 3 subtypes. Appropriate planning for effective interventions for at-risk children of lower socioeconomic status should be considered by the relevant decision-makers.

\section{Inégalités socioéconomiques et maltraitance de l'enfant chez des écoliers iraniens}

RÉSUMÉ Les inégalités socioéconomiques et la maltraitance chez l'enfant n'ont pas été étudiées à l'aide de l'indice de concentration en tant qu'indicateur d'inégalités. La présente étude visait à évaluer l'association entre la maltraitance chez l'enfant et le statut socioéconomique chez des écoliers de la province de Qazvin (République islamique d'Iran). Dans une étude transversale, un questionnaire reposant sur I'outil de dépistage de la maltraitance envers l'enfant de I'ISPCAN, et sur le questionnaire sur les expérience de victimisation des jeunes (Juvenile Victimization Questionnaire) a été rempli par 1028 enfants âgés de neuf à quatorze ans, sélectionnés dans un échantillon aléatoire stratifié à plusieurs degrés. Les indices de concentration pour les inégalités économiques étaient de - 0,086 pour tout type de maltraitance chez l'enfant et de - 0,155, 0,098 et - 0,139 pour les sous-types de maltraitance physique, psychologique et par négligence, respectivement. La maltraitance chez l'enfant dans les trois sous-types était aussi fortement associée au nombre d'enfants et à la situation économique de la famille. Une planification appropriée d'interventions efficaces pour les enfants à risque ayant un statut socioéconomique plus faible doit être envisagée par les décideurs concernés. 


\section{Introduction}

The future well-being of a nation hinges on the health of its children because they represent the future. Ignoring children's needs can compromise their educational preparedness, occupational pursuits, productivity and longevity (1). Child maltreatment is considered a type of violence which affects the health and well-being of many children (2). According to the World Health Organization (WHO) definition, "child maltreatment is all forms of physical and or emotional ill treatment, sexual abuse, neglect or negligent treatment or commercial or other exploitation, resulting in actual or potential harm to the child's health, survival, development or dignity in the context of a responsibility, trust or power" (3). In this context, a child is considered any person below the age of 18 years. From the definitions of the National Child Maltreatment and Neglect Data System and the WHO, child maltreatment includes 5 subtypes: physical abuse; emotional abuse; sexual abuse; neglect and negligent treatment; and exploitation $(4,5)$. On the basis of international studies, a quarter of all adults have been physically abused in childhood, while emotional abuse and neglect are reported in many children. The 41000 homicide deaths of children under 15 years of age reported annually worldwide are likely to be an underestimate of the true extent of the problem as a significant proportion of the reported deaths due to child abuse is incorrectly attributed to unintentional accidents (6). The risk of aggression, developmental delay, antisocial behaviour, lack of successful interaction with others, psychiatric disorders and low self-esteem is greater in maltreated children (7).

The prevalence of child abuse and neglect has been studied before in the Islamic Republic of Iran. In a study in Qazvin province the proportions of positive cases for each of emotional, physical abuse and neglect were $60.1 \%$,
$35 \%$ and $38.3 \%$ respectively (8). In a similar study in Tehran, the prevalences of mental, mild physical, severe physical and neglect child maltreatment were $62.5 \%, 38.3 \%, 35.9 \%$ and $20.5 \%$ respectively (9).

Health inequalities linked to socioeconomic status are an issue of growing importance worldwide (7,10-12). In the context of child maltreatment an association between socioeconomic status and child maltreatment has been found in various studies (13-16). For example, a study conducted on 13-16-year-old students in China showed a range of mild to severe child maltreatment which was higher in children of lower socioeconomic status (14). Studies conducted in the United States of America (USA) and the United Kingdom also showed that poverty and parents' lower levels of education were risk factors for child maltreatment $(15,16)$. To our knowledge there have been no previous studies of child maltreatment using the concentration index as an indicator of socioeconomic inequality.

Qazvin province is a located in the north-western region of the Islamic Republic of Iran, having 25 cities and 898 rural areas, containing a population of about 1200000 of various social and economic classes. Hence it was considered a suitable region to study the parameters of socioeconomic inequality. The objectives of this study were to assess the association of child maltreatment with socioeconomic status and to present the magnitude of the potential socioeconomic inequality of child maltreatment through the concentration index.

\section{Methods}

\section{Study population and sampling}

In this cross-sectional study, 1036 students of school grades 4 and 5 (i.e. aged 9-14 years) in 25 primary schools of
Qazvin province were selected through multistage, stratified random sampling. First, 25 cities were classified into 3 economic classes of poor, middle and rich as the sampling strata. The rural areas were also classified into non-deprived and deprived areas. This stratification was on the basis of expert opinion sessions with key persons who worked in the municipality of Qazvin and who were permanent inhabitants of Qazvin. The next step was determining the number of students in each group, the sex ratio and the ratio of each group in the total population. Then, schools were randomly chosen from the alphabetical list of schools in the 5 above-mentioned economically classified regions and in each selected school we randomly chose some classes in a way that the number of students could reach the minimum estimated sample size for that school. The inclusion criteria were adequate literacy and the absence of visual defects in order for the students to fill the questionnaire properly. Considering $P=0.5, d=0.2$ and design effect $=1.2$ (in the statistical formula) the estimated sample size was 960 students. For feasibility we choose all the students in one selected class and the final sample size was 1036. The questionnaire was self-completed by the students.

\section{Ethical aspects}

This study was approved by the ethics committees of Qazvin and Tehran Universities of Medical Sciences. Written consent to participate in the study was obtained from the students and their parents with the cooperation of the school staff. Since parents did not wish their children to be asked questions regarding sexual maltreatment, this aspect was not assessed in this study. The parents were assured that the data would remain confidential to the parent-teacher meeting. The number of parents who did not cooperate was 8 ; there was no refusal to participate by students, in fact, they were eager to participate because of their teachers' encouragement. In the 
case of the 8 parents, we explained the research finding applications to them again and mentioned that their decision was respected and would not have any effect on the school staff behaviour with their children.

According to Iranian law, punishment of children by parents with the intention of educating and disciplining a child is not considered a crime. For some years there has been a debate between legal experts, sociologists and social activists on the limits of punishment. Therefore, the law can only intervene in severe cases and we could only report cases of severe physical child maltreatment to the legal authority. These cases were those with signs such as bruises and burns on their bodies. However, educational classes on the appropriate behaviour with children were held for all the parents of the chosen schools.

\section{Data collection tool}

Data were collected through a valid and reliable questionnaire in November and December 2011. The primary draft of the questionnaire was derived from 2 standard screening tools: the International Society for the Prevention of Child Abuse and Neglect (ISPCAN) Child Maltreatment Screening Tool-Children's Version (ICAST-C) for 20 questions (17), and the Juvenile Victimization Questionnaire (18) for 3 questions. The ICAST-C questionnaire was completely translated into Farsi, but for the Juvenile Victimization Questionnaire we adopted and translated just 3 questions. The extracted questions were finalized after being reviewed by authorized experts. Four questions were added by our experts on the basis of Iranian culture. The final questionnaire had 3 subtypes of child maltreatment: physical, psychological and neglect.

To assess the content validity of the questionnaire, we sought the opinions of relevant experts, which yielded ratings of $94.1 \%, 83.6 \%$ and $100 \%$ for relevancy, clarity and comprehensiveness respectively.
A 2-stage pilot test was carried out on 24 students of 2 boys' and girls' primary schools through convenience sampling, in which the interval time was 2 weeks. The cases were selected from school grades 4 and 5. Through piloting we made sure of the children's ability to comprehend and respond to the questions. The intra-class correlations and $95 \%$ confidence intervals (CI) for each question and each domain of child maltreatment, calculated separately, were 0.95 (95\% CI: 0.89-1.00), 0.92 (95\% CI: $0.82-0.98)$ and 0.98 (95\% CI: 0.91-1.00) for physical, psychological and neglect subtypes respectively. Cronbach alpha was 0.98, 0.96 and 0.83 for each of the above-mentioned subtypes respectively.

Data were collected on demographic characteristics: the child's sex, area of residence (urban or rural), parents' educational level (illiterate, primary school, middle school, high school and diploma, academic education), father's employment status (employed, unemployed), mother's employment status (employed, housewife) and the number of children in the family $(1,2,3,4$ or more). Parents filled in a questionnaire at home about their level of education and employment status. The economic situation of the family was assessed by questions about the family's wealth and property, including ownership of the following: house (and number of rooms in the house), refrigerator, freezer, colour television (LCD/LED), microwave oven, car, washing machine, personal computer (desktop, laptop) and vacuum cleaner. The asset questions were also filled in by students' parents. From this we calculated the wealth index of the households, which is the most common method of assessing economic status in inequality studies and big surveys.

The maltreatment questionnaires were completed in the classrooms by the children under the supervision of the research team; the average time needed to complete the questionnaires was about 37 minutes. The researchers asked the children not to leave any question blank and they checked that all the questions were answered after the filled questionnaires had been handed in.

\section{Data analysis}

Based on similar studies $(17,18)$ and on the relevant experts' opinions, the questionnaire's response options were designed as 3 options: "no/never", "yes but a little/sometimes" and "yes/always". Child maltreatment was considered if the response to at least one question was "yes" in any of the subtypes of maltreatment.

The socioeconomic status of the children's families was calculated on the basis their assets using the principal component analysis method $(19,20)$. This variable classifies the community into 5 quintiles, each $20 \%$ of the population, ranging from the 1 st to the 5 th groups to indicate the poorest to richest levels in the community respectively.

The concentration index (and 95\% CI of the index) was calculated to quantify the degree of socioeconomic inequality in the child maltreatment variable (20). The concentration index is bounded between -1 and 1 . In cases where there is no socioeconomic inequality, the concentration index is 0 . Negative values of the index indicate that there is a disproportionately higher occurrence or presence of a variable in the poorer group and vice versa for positive values of the index.

Factors associated with child maltreatment were analysed through chi-squared tests and multiple logistic regression. Child maltreatment in each domain was considered as the dependent variable. Children who did not report maltreatment in any of the subtypes were considered not maltreated, while for each subtype the negative outcome was considered if there was even one question answered "yes". The independent variables consisted of the number of children in the family, socioeconomic situation of the family, 
mother's employment status, father's employment status and parents' education. Because of the colinearity between the mother's and father's education, a new variable was defined as parent's education in which the higher education of one of the parents was registered and analysed.

Statistical analysis was done using Stata, version 9, and SPSS, versions 11.5 and 16. Type I error was considered as 0.05 for the results analysis.

\section{Results}

Eight out of 1036 questionnaires were eliminated because they had more than 5 incomplete responses and therefore 1028 questionnaires which had less than 5 unanswered questions were analysed. We removed missing questions from the analysis.

The mean and standard deviation (SD) of age of participants was 10.7 (SD 1.1) years (range 9-14 years). The characteristics of the participants and their families are shown in Table 1. There were slightly more boys than girls among the participants. The most common family size was 2 children (44.0\%). Around half of the parents had a diploma or a higher degree.

\section{Prevalence of child maltreatment}

The prevalence of child maltreatment was $61.5 \%, 35.7 \%$ and $38.0 \%$ in the 3 subtypes of psychological, physical and neglect respectively. The total prevalence (i.e. the prevalence of experiencing at least one type of child maltreatment) was $66.1 \%$. Based on our results, the family members who most often maltreated the child were his/her brother or sister (13.4\%), father (4.3\%) and mother (4.1\%).

All the prevalence values have been presented in another article by city, region and demographic variables (8). Table 2 shows the prevalence of children maltreated in the psychological,

\begin{tabular}{|c|c|c|}
\hline Variable & No. & $\%$ \\
\hline \multicolumn{3}{|l|}{ Sex } \\
\hline Female & 488 & 47.5 \\
\hline Male & 540 & 52.5 \\
\hline \multicolumn{3}{|l|}{ Father's employment status } \\
\hline Employed & 999 & 97.2 \\
\hline Unemployed & 29 & 2.8 \\
\hline \multicolumn{3}{|l|}{ Mother's employment status } \\
\hline Housewife & 183 & 17.8 \\
\hline Employed & 845 & 82.2 \\
\hline \multicolumn{3}{|l|}{ Parent's education } \\
\hline Illiterate & 40 & 3.9 \\
\hline Primary school (grades 1-5) & 202 & 19.6 \\
\hline Middle school (grades 6-8) & 275 & 26.8 \\
\hline High school/diploma & 264 & 25.7 \\
\hline University education & 243 & 23.6 \\
\hline \multicolumn{3}{|l|}{ No. of children in family } \\
\hline 1 & 113 & 11.0 \\
\hline 2 & 452 & 44.0 \\
\hline 3 & 269 & 26.2 \\
\hline$\geq 4$ & 194 & 18.8 \\
\hline
\end{tabular}

physical and neglect domains and any type of maltreatment by the independent variables. The economic status of households was highly significantly associated with the all subtypes of maltreatment $(P<0.001)$. Mother's employment status and parent's education were significantly associated with neglect maltreatment, while family size was associated with physical maltreatment and neglect.

\section{Factors associated with child maltreatment}

Table 3 shows the crude and adjusted odds ratios (OR) for variables which had significant associations with child maltreatment scores. All the assumptions of logistic regression were met. As Table 3 shows, economic status had a significant association with all 3 subtypes of child maltreatment in both the bivariate and multiple logistic regression analysis. The number of children in the family had a significant association only with the physical and neglect subtypes but not with the psychological maltreatment score $(P<0.001)$. A higher prevalence of child maltreatment was found in lower socioeconomic status families (OR 4.22; 95\% CI: 2.46-7.24) and in families with more children (OR 1.95; 95\% CI: 1.09-3.49); in other words, the odds of child maltreatment in the poorest quintile was more than 4 times higher than in the richest quintile; and the odds were twice as high for families having the highest number of children compared with families with 1 child. On the other hand, no association was found with place of residence, father's employment status or the sex of the child and so these variables are not presented in Table 3.

The concentration indices of inequality for the psychological, physical and neglect subtypes and the index for any type of child maltreatment are shown in Table 4. This shows an index of -0.086 (95\% CI: -0.076 to -0.096 ) for any type of child maltreatment in families of lower socioeconomic status, and a significantly higher prevalence of child maltreatment for all 3 


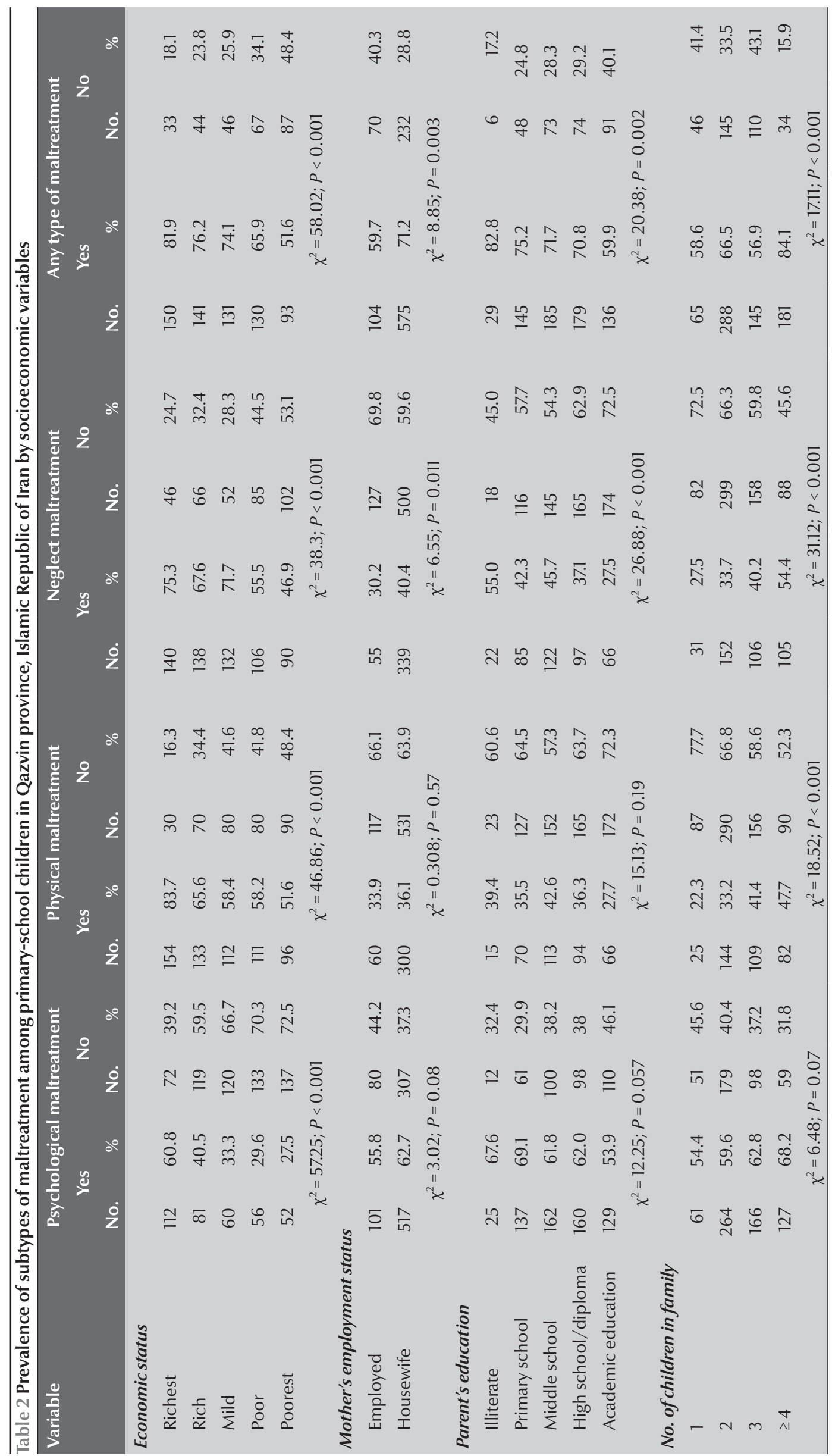




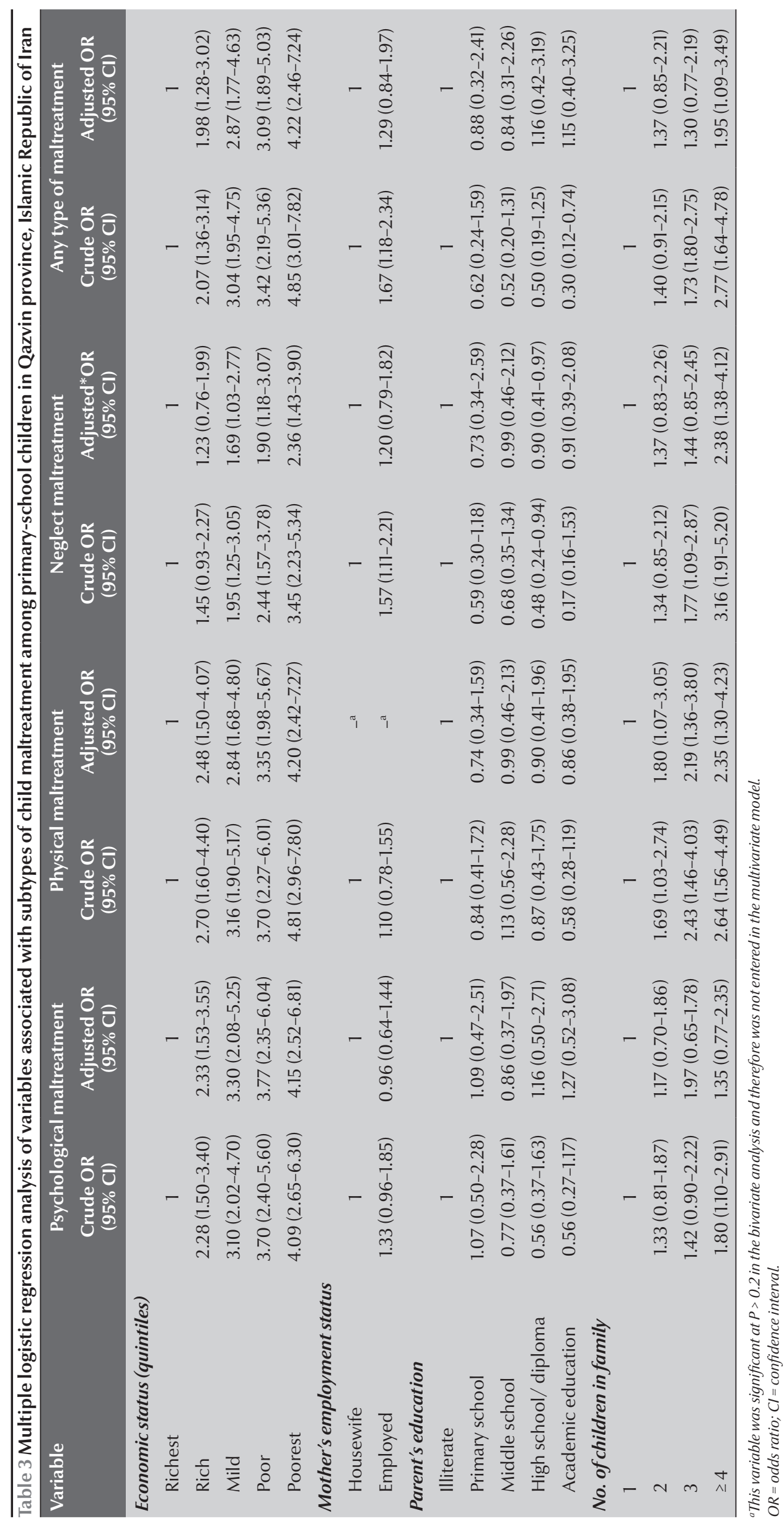




\begin{tabular}{lccc}
\hline Table 4 Concentration index of child maltreatment by subtype & \\
\hline Domain of child abuse & Concentration index & SD & $\mathbf{9 5 \%} \mathbf{C l}$ \\
\hline Psychological & -0.098 & 0.014 & -0.084 to -0.112 \\
Physical & -0.155 & 0.023 & -0.116 to -0.162 \\
Neglect & -0.139 & 0.023 & -0.132 to -0.178 \\
Any type & -0.086 & 0.010 & -0.076 to -0.096
\end{tabular}

$S D=$ standard deviation of concentration index; $C I=$ confidence interval.

studied subtypes of maltreatment in these families.

\section{Discussion}

The results of this study showed that economic inequality was present for all subtypes of child maltreatment; an increasing prevalence of child maltreatment could be observed from the poorest to the richest groups in the community and the victims of this type of violence were most commonly found among the children of poorer socioeconomic classes. A study in the USA also showed a greater prevalence of child maltreatment in the lower economic classes of communities (21), while data from the National Child Abuse and $\mathrm{Ne}$ glect Data System in the USA showed that income inequality had a positive and significant association with child maltreatment rates at the county level (22). Physical violence against children in families with low income and low educational level was also found to be more prevalent in studies from Bangladesh, Colombia, Italy, Sudan, Thailand and England (5). A study on students of 35 North American and European countries during the school year 2001-02 showed more home violence among families with an undesirable socioeconomic situation (23). Since the ability to provide even the essential needs of children is impossible or very difficult for parents in poor families, neglect and physical and psychological child maltreatment are seen significantly more in these families than those with middle and high income, perhaps due to stress and the poor mental health among members of the family $(24,25)$. A distinction, however, should be made between failure to provide for the child because of poverty or because of neglect (i.e. the ability to provide by failure to do so).

Fortunately, the results of the current study did not show any gender associations with any subtype of child maltreatment, although this kind of inequality can be seen in studies in other countries. For example, the results of the study by Machado et al. in Portugal showed a higher prevalence of maltreatment of girls (26).

The currentstudy showed a decrease in child maltreatment with an increase in the parents' educational level, which is in accordance with the findings of other studies $(18,25)$. In a study in the USA in 2009, children who lived in poor families with single parents experienced more maltreatment compared with the children who lived in better educated and richer families (27). The results of our study, however, did not show a significant association between child maltreatment and mothers' and fathers' employment status, after adjustment for the effect of other variables.

Among other factors that might affect child maltreatment, the number of children in the family showed a direct association with child maltreatment in the current study. The family members who most often maltreated the child were brothers or sisters, while fathers and mothers were less likely to be involved. In another study in the Islamic Republic of Iran, in Tehran, child maltreatment was more frequently carried out by mothers of lower socioeconomic classes, which may be due to the greater time spent with the children (28). In a study in Pakistan in 2013, greater child abuse was reported among children whose mothers were not satisfied with their marital life, were of lower educational level and had a stressful home environment (29).

As the phenomenon of child maltreatment is affected by violence in the home, decision-makers for social affairs need to plan special programmes to provide local services for alleviating the problem. Some social critics still believe that punitive measures against parents areineffective and that more effective and concrete measures should be taken (30). All individuals below the age of 18 years are covered by the Child Protection Law, which was approved by the Iranian parliament in 2002. The law contains 9 items on the protection of children and adolescents and prohibits all types of harm leading to physical, psychological and spiritual damage to children and adolescents and threats to their physical or mental health. It seems, however, that the laws to protect children's rights are poorly protected by sanctions. In the cultural context, according to the law of 2002 and the Islamic penal code, punishing children is permissible up to a "customary" extent and the judgement about what is customary is assigned to the public. Hence, the matter becomes a subjective one. People in certain local cultures may allow themselves to maltreat their children in the name of punishment. As an initial step, this matter should be solved. Some lawmakers attribute this type of child maltreatment to legal uncertainties, which can be scrutinized. This issue occurs mostly in the framework of child upbringing, and if a parent maltreats a child it is justified in terms of bettering the child's upbringing. Social organizations need to give appropriate education to the families and plan for the implementation of protection programmes, especially in families with 
higher numbers of children and an undesirable economic status.

There were some limitations to the study. Due to our inability to obtain parents' permission, sexual child maltreatment was not assessed in this study. Although the questionnaires were anonymous and avoided specific personal characteristics, there was a possibility of under-reporting bias by the victims of child maltreatment due to fear or shame. Over-reporting due to a low level of comprehension by children or their desire to draw attention to themselves is also possible. However, the scoring approach of the questionnaire was sensitive enough to detect the mild type of maltreatment. Furthermore, the data were collected in primary schools and since some children with severe forms of child maltreatment may be deprived of education at school, this may also cause underestimation of the prevalence of maltreatment due to this selection bias. Finally, we did not collect data on potential confounders such as family discord, children's behaviour or parenting style.

In conclusion, since socioeconomically deprived groups in the community are at high risk for child maltreatment, appropriate planning for effective intervention in these groups should be considered by the relevant decisionmakers in social affairs. The effectiveness of these interventions should be evaluated in future research. These findings may be useful for decision-makers in the health and education ministries to identify the children at high risk for maltreatment.

\section{Acknowledgements}

The authors offer their thanks to the Department of Education of Qazvin for their cooperation in data collection. This project was the MSc thesis of Zahra Hosseinkhani (proposal number 8910-7-3562) at Tehran University of Medical Sciences.

Funding: The study was funded by Qazvin University of Medical Sciences and Tehran University of Medical Sciences.

Competing interests: None declared.

\section{References}

1. Hernandez VR, Montana S, Clarke K. Child health inequality: framing a social work response. Health Soc Work. 2010 Nov;35(4):291-301. PMID:21171536

2. Giardino AP. Child abuse/treatment. In: Kris H, editor. International encyclopedia of public health. Oxford: Academic Press; 2008. pp. 571-83.

3. Krug EG, Dahlberg LL, Mercy JA, Zwi AB, Lozano R. World report on violence and health. Geneva: World Health Organization; 2000.

4. Health topics: child maltreatment [Internet]. Geneva: World Health Organization (http://www.who.int/topics/child_ abuse/en/, accessed 4 August 2015).

5. Gorey KM, Leslie DR. The prevalence of child sexual abuse: integrative review adjustment for potential response and measurement biases. Child Abuse Negl. 1997 Apr;21(4):391-8. PMID:9134267

6. Child maltreatment. Fact sheet No.150. Updated December 2014 [Internet]. Geneva: World Health Organization; 2014 (http://www.who.int/mediacentre/factsheets/fs150/en/, 4 August 2015).

7. Fang P, Dong S, Xiao J, Liu C, Feng X, Wang Y. Regional inequality in health and its determinants: evidence from China. Health Policy. 2010 Jan;94(1):14-25. PMID:19735959

8. Mahram M, Hosseinkhani Z, Nedjat S, Aflatouni A. Epidemiologic evaluation of child abuse and neglect in schoolaged children of Qazvin province, Iran. Iran J Pediatr. 2013 Apr;23(2):159-64. PMID:23724176

9. Khoushabi K, Habibi-Asgarabad M, Farzadfard SZ, Mohammadkhani P. Investigating prevalence of child abuse among guidance school students, Tehran: 2009-2010. Soc Welfare (India). 2008;7(27):115-35 [In Persian].

10. Nedjat S, Hosseinpoor AR, Forouzanfar MH, Golestan B, Majdzadeh R. Decomposing socioeconomic inequality in selfrated health in Tehran. J Epidemiol Community Health. 2012 Jun;66(6):495-500. PMID:21282143

11. Ostlin P, Braveman P, Dachs N, Dahlegren G, Diderichsen F, Harris E, et al.; WHO Task Force on Research Priorities for
Equity in Health; WHO Equity Team. Priorities for research to take forward the health equity policy agenda. Bull World Health Organ. 2005 Dec;83(12):948-53. PMID:16462988

12. Starfield B. Equity in health. CMAJ. 2000 Feb 8;162(3):346. PMID:10693592

13. Vallgårda S. Social inequality in health: dichotomy or gradient? A comparative study of problematizations in national public health programmes. Health Policy. 2008 Jan;85(1):71-82. PMID:17706317

14. Wong WCW, Chen WQ, Goggins WB, Tang CS, Leung PW. Individual, familial and community determinants of child physical abuse among high-school students in China. Soc Sci Med. 2009 May;68(10):1819-25. PMID:19344989

15. Sidebotham P, Heron J; ALSPAC Study Team. Child maltreatment in the "children of the nineties": a cohort study of risk factors. Child Abuse Negl. 2006 May;30(5):497-522. PMID:16701895

16. Weissman AM, Jogerst GJ, Dawson JD, Jogerst GJ, Dawson JD. Community characteristics associated with child abuse in Iowa. Child Abuse Negl. 2003 Oct;27(10):1145-59. PMID:14602096

17. Zolotor AJ, Runyan DK, Dunne MP, Jain D, Péturs HR, Ramirez C, et al. ISPCAN Child Abuse Screening Tool Children's Verd sion (ICAST-C): Instrument development and multi-national pilot testing. Child Abuse \&amp. Neglect. 2009;33(11):833-41.

18. Finkelhor D, Hamby SL, Ormrod R, Turner H. The juvenile victimization questionnaire: reliability, validity, and national norms. Child Abuse Negl. 2005 Apr;29(4):383-412. PMID:15917079

19. Gwatkin DR, Rutstein S, Johnson K, Suliman E, Wagstaff A, Amozou A. Socioeconomic differences in health, nutrition, and population with in developing countries: an over view. JAMA. 2007;298:1943-4.

20. Van de Poel E, Hosseinpoor AR, Speybroeck N, Van Ourti T, Vega J. Socioeconomic inequality in malnutrition in developing countries. Bull World Health Organ. 2008 Apr;86(4):28291. PMID:18438517 
21. Zielinski DS. Child maltreatment and adult socioeconomic well-being. Child Abuse Negl. 2009 Oct;33(10):666-78. PMID:19811826

22. Eckenrode J, Smith EG, McCarthy ME, Dineen M. Income inequality and child maltreatment in the United States. Pediatrics. 2014 Mar;133(3):454-61. PMID:24515511

23. Due P, Merlo J, Harel-Fisch Y, Damsgaard MT, Holstein BE, Hetland J, et al. Socioeconomic inequality in exposure to bullying during adolescence: a comparative, cross-sectional, multilevel study in 35 countries. Am J Public Health. 2009 May;99(5):907-14. PMID:19299676

24. Tagikhani SH. Assessment of family characteristics, economicsocial, psychological and coping styles of parents with child abuse behaviour [Thesis]. Vanak, Islamic Republic of Iran: Department of Psychology and Educational Sciences, Azzahra University; 2002 [in Persian].

25. Sahbaei F, Davachi A, Zeraati Najafi Z. The relationship between family factors, social, and psychological abuse of public primary schools for girls in Tehran. Journal of Medical Sciences University. 2006;16(1):43-8 [in Persian].

26. Machado C, Gonçalves M, Matos M, Dias AR. Child and partner abuse: self-reported prevalence and attitudes in the north of Portugal. Child Abuse Negl. 2007 Jun;31(6):657-70. PMID:17617457

27. Merritt DH. Child abuse potential: correlates with child maltreatment rates and structural measures of neighborhoods. Child Youth Serv Rev. 2009;31(8):927-34.

28. Rahimi Movaghar A. The prevalence of child abuse in the Tehran area. Journal of Social Welfare. 2003;7(1):141 [In Persian].

29. Ali NS, Ali FN, Khuwaja AK, Nanji K. Magnitude and factors associated with child abuse in a mega city of developing country Pakistan. Iran J Pediatr. 2014 Apr;24(2):140-6. PMID:25535531

30. Humphreys C. A health inequalities perspective on violence against women. Health Soc Care Community. 2007 Mar;15(2):120-7. PMID:17286673 